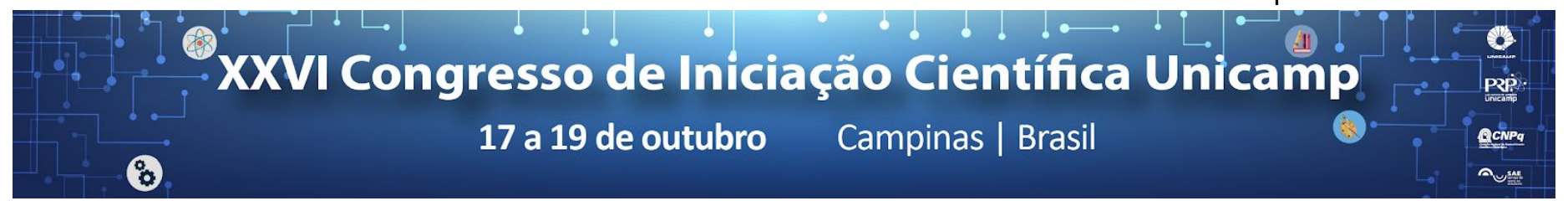

\title{
Células eletrolíticas como motivação para o estudo da química
}

\author{
Lucas R. de F. Fonseca*, Breno G. F. Correa, Adriane J. S. Silva, Carlos C. Lima, Marta V. F. Rodrigues, Pablo S. \\ Fernández, Rafael Alcides Vicente.
}

\section{Resumo}

Este trabalho está sendo realizado no contexto do projeto PIBIC-EM, onde a eletroquímica está servindo de motivação para o estudo de tópicos fundamentais da química como balanceamento de equações químicas, preparação de soluções, cálculos de concentrações, etc. e para problemas atuais e de importância em nosso país como o aproveitamento da biomassa.

Palavras-chave: Eletroquímica, eletrólise, cobre.

\section{Introdução}

A eletroquímica é uma área da Físico-química que estuda a geração de energia elétrica devido à ocorrência de reações químicas ou, o processo inverso, ou seja, a produção de substâncias químicas através do uso da energia elétrica ${ }^{1}$. Neste trabalho construímos dispositivos simples com os quais estudamos diversas reações eletroquímicas. Na figura 1 mostramos um sistema eletroquímico com o qual depositamos $\mathrm{Cu}$ metálico aplicando diferentes correntes em eletrodos de grafite obtidos de descartes de pilhas alcalinas de uso convencional. Este experimento simples permitiu que os alunos desenvolvessem habilidades relacionadas com o trabalho experimental e de cálculos de estequiometria.

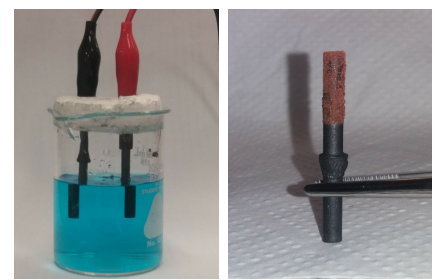

Figura 1. Eletrodos de grafite mergulhados em uma solução de $\mathrm{CuSO}_{4}$. No cátodo acontece a redução dos íons $\mathrm{Cu}^{+2}$ e no ânodo a oxidação de água para $\mathrm{O}_{2}$. $\mathrm{Na}$ figura da direita pode se ver o depósito do metal.

\section{Resultados e Discussão}

A tabela 1 mostra os resultados obtidos aplicando diferentes diferenças de potencial $(E)$ entre os eletrodos. Assim que aumentamos $\mathrm{E}$ aumenta a corrente que flui entre os eletrodos (I). Cada $E$ foi aplicada por 10 minutos e o eletrodo foi pesado antes e depois da deposição (M). Determinamos que a massa de Cu depositada aumentou com o aumento da I. Conhecendo I, o tempo e as leis de Faraday ${ }^{1}$ calculamos a massa teórica de $\mathrm{Cu}$ depositada $\left(\mathrm{M}_{\mathrm{t}}\right)$, ou seja, a $\mathrm{M}$ que teríamos que ter pesado se todos os elétrons que circulam pelo circuito forem utilizados para reduzir os íons $\mathrm{Cu}^{+2}$ no cátodo. Considerando a diferença entre $M$ e $M_{t}$, calculamos a porcentagem dos elétrons que foram utilizados para depositar o $\mathrm{Cu}(\mathrm{Ef})$. Como pode se observar na tabela, com o aumento de $\mathrm{E}$ e de I diminui a porcentagem de elétrons utilizados para depositar o metal. Assim que aumentamos E, fornecemos energia para que uma maior quantidade de reações possam acontecer. Como o experimento foi feito em meio aquoso, no cátodo pode acontecer a redução da água para formar $\mathrm{H}_{2}$, assim, grande parte dos elétrons que não são utilizados para depositar $\mathrm{Cu}$ provavelmente reagem com a água para formar $\mathrm{H}_{2}$.

\begin{tabular}{|c|c|c|c|c|}
\hline $\boldsymbol{E} / \boldsymbol{V}$ & $\boldsymbol{I} \boldsymbol{A}$ & $\boldsymbol{M} / \mathbf{m g}$ & $\boldsymbol{M}_{\boldsymbol{t}} / \mathbf{m g}$ & $\boldsymbol{E f}$ \\
\hline 4 & 0,08 & 9,6 & 7,9 & 82 \\
\hline 6 & 0,14 & 21,2 & 13,8 & 65 \\
\hline 7 & 0,18 & 36,0 & 17,8 & 49 \\
\hline 8 & 0,25 & 62,0 & 24,7 & 40 \\
\hline 9 & 0,36 & 101,0 & 35,6 & 35 \\
\hline
\end{tabular}

Tabela 1. Dados de diferença de potencial $(E)$, corrente (I), massa de $\mathrm{Cu}$ depositada $(\mathrm{M})$, massa teórica do $\mathrm{Cu}\left(\mathrm{M}_{\mathrm{t}}\right)$ e eficiência (Ef) para os 5 experimentos realizados neste trabalho.

Por último, utilizando uma impressora 3D, temos construído uma célula eletrolítica com a qual estamos estudando a eletrólise da água em solução de $\mathrm{NaOH}$ com e sem glicerol. Este dispositivo está nos permitindo coletar os gases formados no ânodo e no cátodo, o qual tem nos permitido introduzir novos conceitos como, por exemplo, a lei dos gases ideais ${ }^{2}$.

\section{Conclusões}

A eletrólise é uma ferramenta extremamente interessante para motivar os alunos a estudarem grande parte dos conceitos da química geral. Os alunos que participaram deste trabalho aprenderam muitos conceitos básicos que não tiveram contato no ensino médio. Utilizando ferramentas simples e de baixo custo podem-se realizar experimentos que possibilitam obter resultados altamente precisos e que mostrem as alternativas tecnológicas que a eletroquímica oferece para solucionar problemas diversos de cunho ambiental e industrial.

\section{Agradecimentos}

FAPESP
FAEPEX.

Ticianelli, Edson A., Gonzalez, Ernesto R. Eletroquímica. Edusp - Editora da Universidade de São Paulo, 2013.

2 Kotz, John C., Treichel, Paul M., Townsend, John R.,, Treichel, David A. Chemistry and Chemical Reactivity. 9th edition. Cengage Learning, 2016. 